\title{
EDITORIAL
}

\section{ROAD SAFETY IN KENYA}

Unfortunately, road safety trends in Kenya are worsening.

The mean annual fatality rate from all road traffic accidents in Kenya is estimated at 50 deaths per 10000 registered vehicles $(1,2)$. The numbers of reported accidents have been showing an increasing trend from 10,300 in 1990 to 16,800 in 2000 and 17,400 in $2009(1,2)$. The annual economic cost of road traffic accidents is 5\% of the country's Gross National Product (1-4).

The first vehicle in Kenya was introduced in 1905. In 1990 Kenya had 350,000 registered units and by 2009 the number had risen to 569,400 representing an average increase of vehicles per year of $0.8 \%$ with a current registration of 150 vehicles per day $(1,3)$.

In Kenya, as it's in most third world countries percentage of all cars and motorcycles owned in the country are based in the capital city(1). Thus, in Thailand for example, about $75 \%$ of all cars are based in Bangkok (with only10\% of the country's population) and in Iran and Kenya, the capital cities of Teheran and Nairobi contain over $50 \%$ of the nation's cars $(1,2,4,5)$. In developing countries higher income people tend to live close to city centers and even if they own personal transport they still make use of local public transport systems $(2,6,7)$. Pedal cyclists also constitute a significant proportion on road victims in developing and emerging countries despite fairly low vehicles populations $(1,2,5,6)$. In Kenya, cyclists have to compete with vehicular traffic for the existing road space. In 1995, pedal cyclists accounted for $11 \%$ of all road fatalities $(1,6)$.

In medium-size towns, cycling provides an attractive mode of urban travel but the main challenge is to maintain traffic safety and to improve the networks of cycling routes. In the big cities, in developing world, like Nairobi, cycling is not possible now without taking a severe accident risk (6-8).

Most injured people in rural areas are transported to hospitals staffed by general practitioners with no training in trauma care $(7,9)$. Even in urban centres, mortality is high because of disorganisation and lack of adequate equipment or trained personnel.

Limitations that explain the poor outcome for people involved in road traffic crashes in Africa have been identified, and include lack of trained surgeons, intensive care staff, and field paramedics; underserved medical facilities; inappropriate dedicated transportation; and disorganised or nonexistent emergency and trauma services (8-10). Impediments to promoting road safety measures in Africa include lack of complete documentation on road traffic "accidents" and the resulting injuries, imprecise surveillance methods, limited research on causes and risk factors, as well as lack of awareness of existing interventions by the public and many policy makers (9-11).

In Kenya the Traffic Police collect all accident data for the purpose of legal prosecution and insurance claims. The accident data P41 form filled at the Police Stations are collated and forwarded to the Roads Department, Ministry of Roads and Public Works for further processing and analysis $(1,12)$. The Roads Department analyses the information in order to determine:

(i) Number and type of injuries

(ii) Cause of accident

(iii) Classification of black spots (determined based on number of fatalities)

Based on the road accident information, the Roads Department prepares work plans for enhancement of road safety at identified black spots and other dangerous locations on public roads (1). This data however does not fully address hospital based information.

RTA epidemiology: Survey of literature in Africa shows that various specialists have carried out research on road safety including those of public health, general surgeons and orthopaedic surgeons (12-20). Though the bulk of research has been carried out by public health personnel most are based on police data $(6,17,19)$. The majority of injuries suffered following road traffic crushes are of orthopaedic concern $(17,20)$.

The traditional role of the orthopaedic surgeon in road safety in Kenya as analysed by Mulimba (17) includes; 

(i) Rescue from the scene of accident
(ii) Resuscitation
(iii)Teaching
(iv) Treatment of victims
(v) Rehabilitation
(vi) Occasional research

Prevention and appropriate management of road traffic injuries must include emphasis on research on road traffic injuries and outcomes (17, 20, 23). For only then will the orthopaedic surgeons be in a position to provide information that can influence the use of gargets such as safety belts, breath analyser and motor vehicle designs for safety (2325).

Conclusion: The road transport system is the dominant form of inland transportation and carries more than $95 \%$ of passenger traffic $(5,21)$. All is well when a road user arrives at his destination safely. When he doesn't arrive safely quite often the input of an orthopaedic surgeon may have been required sooner than later. The orthopaedic surgeon is therefore in a well placed position to be able to collect vital statistics on road traffic injuries. Hence the advocacy that the role of the orthopaedic surgeon in research in road traffic injuries cannot be over emphasized.

F. Otsyeno, SICOT (Dip), FCS (ECSA), MMed (Surg), MBChB, Orthopaedic Surgeon, Kenyatta National Hospital; Chairman, Kenya Orthopaedic Association; National Delegate to SICOT, Kenya; Convenor, Road safety, Kenya Medical Association, P.O. Box 29803 -00202, Nairobi, Kenya. Email Otsyeno@hotmail.com

\section{REFERENCES}

1. Kenya Roads Board.

2. Odero, W., Khayesi, M. and Heda, P.M. Road traffic injuries in Kenya: magnitude, causes and status of intervention. Injury Control and Safety Promotion. 2003: 10; 53-61.

3. SICOT Conference: Road safety 1998 Nairobi, Kenya

4. Yerrel, J.S. Road safety in the countries of Africa: an overview. In: Economic Commission for Africa. First African Road Safety Conference, compendium of papers. Nairobi: Economic Commission for Africa; 1984.

5. Murray, C.J.L. and Lopez, A.D. The global burden of disease. World Health Organization/ Harvard School of Public Health/World Bank. Harvard University Press, 1996.
6. Obara R. Motorcycle injuries in low and middle income countries experiences within Kisumu municipality RTIRN Regional Workshop on motorcycle injuries, Nairobi, Kenya June 23, 2009.

7. Jacobs, G. and Aeron-Thomas, A. (TRL Limited). Africa Road Safety Review: Final Report. Global Road Safety Partnership; 2000. Available at: www. safety.fhwa.dot.gov/fourthlevel/toc.htm.

8. Odero, W. Dean, School of Public Health, Moi University Eldoret, World Health Day 2004.

9. Odero,W.Garner,P. and Zwi, A. Road traffic injuries in developing countries; a comprehensive review of epidemiological studies. Trop. Med. Intern. HIth. 1997; 2(5); 445-460.

10. Mulimba, J.A.O. and Muyembe, V.M. Pattern of road traffic injuries at Kenyatta National Hospital. Medicom. 2000; 15:93-101.

11. Odero, W. Road traffic injuries research in Africa: Context and Priorities: Forum 8 Mexico City 1620 November 2009.

12. Aswoga, S.E. Motorcycle accident casualties and the use of crash helmets. East Afr. Med. J. 1982:59; 550-664.

13. Asogwa, S.E. An overview of auto crashes in Nigeria, 1970-1994. 40th Proceedings of the Association for the Advancement of Automotive Medicine. October 7-9, 1996. Vancouver, British Columbia, 1996: 187-198.

14. Falope, I.A. Motorcycle accidents in Nigeria. A new group at risk. West Afr. J. Med. 1991: 10; 187-189.

15. Zwi, A.B., Gilson, L. and Fox-Rushby, J. Injury surveillance in Zimbabwe: a situational analysis. London School of Hygiene \& Tropical Medicine/ Ministry of Health and Child Welfare, Zimbabwe. London: 1993.

16. African Safety Promotion: Journal of Injury and Violence Prevention. Website: www.unisa.ac.za/ dept/ishs.

17. Mulimba, J.A.O. Key note address to the Kenya Orthopaedic Association, 4th Annual Scientific Conference, Eldoret, Kenya March. 2009.

18. Otieno, T., Woodsfield, J.C., Bird, P. and Hill, A.G. Trauma in rural Kenya: injury. Int. J. Care Injured. 2004: 35; 1228-1233.

19. Odero, W. Road traffic injuries in Africa: a review. East Afr. Med. J. 1994: 71; 339.

20. Odero, W. and Kibosia, J.C. Incidence and characteristics of injuries in Eldoret, Kenya. East Afr. Med. J. 1995: 72; 706-710. 
21. Ghee, C., Astrop, A., Silcock, D. and Jacobs, G.D. Socio economic aspects of road accidents in developing countries. TRL Report TRL 247: Transport Research Laboratory, Crow Thorne, UK; 1997.

22. Odelowo, E.O. Pattern of trauma resulting from motorcycle accidents in Nigerians: a two-year prospective study. Afr. J. Med. Sci. 1994: 23; 109112.
23. Muhlrad, N. Traffic safety research for developing countries: methodologies and first results. Paris: INRETS No. 7; 1987.

24. Kobus, H.J. Breathe analysis for control of drunkdriving in Zimbabwe Rhodesia. Central Afr. J. Med. 1980: 26; 21-27.

25. Van der Spuy, J. Blood alcohol levels in traffic legislation - what is realistic? Trauma Review. 1996: 4(3); 4-5. 